\title{
A New Era in the Treatment of Scleroderma-associated Interstitial Lung Disease?
}

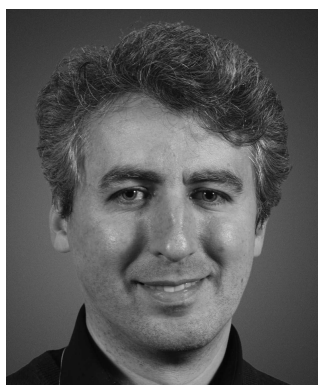

Pulmonary involvement in systemic sclerosis or scleroderma (SSc) is mainly represented by SSc-associated interstitial lung disease (SSc-ILD) and pulmonary hypertension ${ }^{1,2}$. SSc-ILD is a major challenge: It is both a very frequent and a very severe complication of SSc. According to the literature, SSc-ILD is or will be present in around one-half of patients with diffuse SSc, and one-third of patients with limited cutaneous $\mathrm{SSc}^{3}$. SSc-ILD is now one of the leading causes of death in $\mathrm{SSc}^{4}$. This explains why much effort has been expended to understand and better know the characteristics of patients with SSc-ILD as well as to manage them properly. However, despite decades of observational studies and a few randomized ones, the optimal management of patients with SSc-ILD is still a matter of debate. From an historic point of view, the cornerstone of SSc-ILD treatment has mainly been immunosuppressants. This can be explained by the fact that SSc is a connective tissue disease in which inflammation and immune abnormalities play a central role ${ }^{5}$. The immune system, especially in regards to $\mathrm{B}$ and $\mathrm{T}$ lymphocytes, is fully involved in fibroblast activation and fibrogenesis by secreting proinflammatory and profibrotic cytokines and growth factors ${ }^{6}$. The most common immunosuppressant, cyclophosphamide (CYC), has been tested in many open-label studies and a few randomized control trials (RCT), as well as being recommended in the European League Against Rheumatism Scleroderma Trials and Research group guidelines ${ }^{7}$. However, the results of those RCT are still dividing the medical community. In the FAST study, there was no significant difference between the placebo and CYC group ${ }^{8}$. In SLS $1^{9}$, the difference in forced vital capacity (FVC) at 12 months (primary endpoint) was $2.5 \%$ in favor of CYC versus placebo, and the difference was statistically significant. The clinical significance of this modest yet real improvement in FVC is still a matter of debate, and decades of pros and cons lie ahead. A very interesting detail is that patients in SLS1 most probably had a stable SSc-ILD, considering that only $15 \%$ of them needed an immunosuppressive treatment after the end of the study ${ }^{3,10}$.
The modest improvement of SSc-ILD with CYC and other immunosuppressants in patients with stable disease highlights a very important point: SSc-ILD is a very heterogeneous disease. Indeed, SSc-ILD can be very stable or slowly deteriorating, while some patients can worsen faster ${ }^{11}$. It is highly probable that management will differ according to the profile of patients. In line with this statement, the few observational studies that have included SSc-ILD patients with a non-stable, worsening pulmonary disease have shown that CYC was able to stabilize or improve them in a majority of the cases ${ }^{12,13}$. In those patients with worsening disease, it is possible that inflammation and the immune system play a greater role than in stable patients and that immunosuppressants can stop the evolution. As noted before, in this context, stabilization of SSc-ILD can be considered a success $\mathrm{s}^{3,10,14,15}$.

Therefore, if we try to summarize the state of the art in SSc-ILD, immunosuppressants can either stabilize worsening SSc-ILD or modestly improve stable SSc-ILD. One could argue that hematologic stem cell transplantation has yielded better results in SSc-ILD ${ }^{16,17}$. While this is true, this procedure cannot be applied in the vast majority of SSc-ILD patients, but is still to be considered in selected and severe cases.

Is this the end of the story and should we be happy with the available immunosuppressive armentarium and its modest input in SSc-ILD? The answer is clearly no, and much effort has and will be made to improve the management of SSc-ILD. As frequently observed in the rheumatology or internal medicine fields, good ideas can come from other fields of research. The closest comparison with SSc-ILD is idiopathic interstitial lung diseases, such as idiopathic pulmonary fibrosis (IPF). In this latter devastating disease, immunosuppressive treatments are no longer used; rather, a new era is coming with the approval of antifibrotic agents such as pirfenidone ${ }^{18}$ and nintedanib ${ }^{19}$. These 2 treatments have been shown to delay the worsening of patients with IPF, and for the first time, to improve survival ${ }^{18,19}$. It is

See Pirfenidone scleroderma-associated ILD, page 1672

Personal non-commercial use only. The Journal of Rheumatology Copyright (c) 2016. All rights reserved. 
very tempting to think that they could be useful in SSc-ILD. Indeed, SSc-ILD and IPF share many pathophysiological pathways, such as fibroblast activation, myofibroblast accumulation, and expression of fibrogenic cytokines and growth factors; and both pirfenidone and nindetanib can target them. Limiting fibrogenesis using antifibrotic treatments and inflammation/immunological abnormalities by immunosuppressants could become the new paradigm of treatment in SSc-ILD. In line with this hypothesis, some observational case reports suggest that pirfenidone could be useful in SSc-ILD ${ }^{20,21}$.

However, we should also be very cautious: SSc-ILD is not IPF. The main differences are that patients with SSc-ILD have SSc, a systemic disease, and not only a lung disease. The effects of these new antifibrotic treatments, whether beneficial or deleterious to other involved organs in SSc, will undoubtedly be major topics of future studies. Moreover, great hope can also be associated with great disappointment. We have to remember the example of imatinib, which was very promising but which failed to show any efficacy in RCT and was associated with severe side effects, precluding its use in $\mathrm{SSc}^{22,23,24}$.

In this context, the LOTUSS study presented by Khanna, et al in this issue of The Journal should be considered a very smart and important contribution in the field of SSc-ILD ${ }^{25}$. The authors chose to carefully assess the tolerability of pirfenidone before assessing its efficacy in a larger RCT in SSc-ILD. Indeed, pirfenidone can be associated with adverse events of the gastrointestinal (GI) system and the skin in patients with IPF, 2 organs very frequently involved in SSc-ILD. Sometimes these adverse events can lead to drug discontinuation ${ }^{26}$. If pirfenidone is efficient in SSc-ILD but worsens the GI manifestation of SSc, it could be a major problem for the future use of this drug in daily clinical practice. In the LOTUSS study, 63 patients with SSc-ILD were randomized to receive either a 2- or a 4-week titration starting at $801 \mathrm{mg} /$ day and aiming to finish at a maintenance dose of $2403 \mathrm{mg} /$ day $^{25}$. In IPF, the 2-week titration is usually used, but the authors, anticipating more adverse events in SSc-ILD, chose to also test a longer titration period. The main finding of the study is that adverse events of pirfenidone in SSc-ILD were similar to those observed in IPF, regardless of the titration schedule. The most common side effect was nausea, which was severe in $2.1 \%$ and $3.2 \%$ of patients in the 2 -week and 4-week titration group, respectively. Moreover, assessment of GI symptoms using a validated questionnaire was similar between groups, even when patients were receiving mycophenolate mofetil, which can also be associated with similar side effects. However, interestingly, 5 patients in the 2 -week titration period versus 1 patient in the 4-week titration period discontinued pirfenidone. Serious adverse events were observed in 3 patients, all in the 2-week titration period. By performing this very important study, Khanna, et al thus show that pirfenidone has an acceptable tolerability profile in SSc-ILD but that the usual 2-week titration could be associated with more side effects ${ }^{25}$. Therefore, the authors recommend a 4-week titration schedule for future trials. Of course, the authors also assessed some efficacy variables and showed very stable results. However, LOTUSS was not designed to assess efficacy on a short, 16-week study period.

The LOTUSS study presented in The Journal 25 probably opens a new era in SSc-ILD. First, assessing the tolerability profile of a new drug is mandatory in SSc-ILD. Second, although targeting fibrogenesis could yield very promising results, RCT have to firmly demonstrate the efficacy of this strategy in SSc-ILD.

\section{DAVID LAUNAY, MD, $\mathrm{PhD}$,}

Lille University, U995,

Lille Inflammation Research International Center;

INSERM, U995;

CHU Lille, Département de Médecine Interne et Immunologie Clinique; CHU Lille, National Reference Centre for Scleroderma,

Lille, France.

Address correspondence to Prof. D. Launay, Service de Médecine Interne, Hôpital Claude-Huriez, CHRU Lille, rue Michel Polonovski, F-59037 LILLE Cedex, France. E-mail: david.launay@univ-lille2.fr

\section{REFERENCES}

1. Le Pavec J, Launay D, Mathai SC, Hassoun PM, Humbert M. Scleroderma lung disease. Clin Rev Allergy Immunol 2011; 40:104-16.

2. Sobanski V, Launay D, Depret S, Ducloy-Bouthors AS, Hachulla E. Special considerations in pregnant systemic sclerosis patients. Expert Rev Clin Immunol 2016 Jun 8 (E-pub ahead of print).

3. Wells AU. Interstitial lung disease in systemic sclerosis. Presse Med 2014;43:e329-43.

4. Steen VD, Medsger TA. Changes in causes of death in systemic sclerosis, 1972-2002. Ann Rheum Dis 2007;66:940-4.

5. Hachulla E, Launay D. Diagnosis and classification of systemic sclerosis. Clin Rev Allergy Immunol 2011;40;78-83.

6. Sanges S, Guerrier T, Launay D, Lefèvre G, Labalette M, Forestier A, et al. Role of B cells in the pathogenesis of systemic sclerosis. Rev Med Interne 2016 Mar 25 (E-pub ahead of print).

7. Kowal-Bielecka O, Landewe R, Avouac J, Chwiesko S, Miniati I, Czirjak L, et al. EULAR recommendations for the treatment of systemic sclerosis: a report from the EULAR Scleroderma Trials and Research group (EUSTAR). Ann Rheum Dis 2009;68:620-8.

8. Hoyles RK, Ellis RW, Wellsbury J, Lees B, Newlands P, Goh NS, et al. A multicenter, prospective, randomized, double-blind, placebo-controlled trial of corticosteroids and intravenous cyclophosphamide followed by oral azathioprine for the treatment of pulmonary fibrosis in scleroderma. Arthritis Rheum 2006;54:3962-70.

9. Tashkin DP, Elashoff R, Clements PJ, Goldin J, Roth MD, Furst DE, et al. Cyclophosphamide versus placebo in scleroderma lung disease. N Engl J Med 2006;354:2655-66

10. Khanna D, Nagaraja V, Tseng CH, Abtin F, Suh R, Kim G, et al. Predictors of lung function decline in scleroderma-related interstitial lung disease based on high-resolution computed tomography: implications for cohort enrichment in systemic sclerosis-associated interstitial lung disease trials. Arthritis Res Ther 2015;17:372.

11. Bouros D, Wells AU, Nicholson AG, Colby TV, Polychronopoulos V, Pantelidis P, et al. Histopathologic subsets of fibrosing alveolitis in patients with systemic sclerosis and their relationship to outcome. Am J Respir Crit Care Med 2002;165:1581-6.

Personal non-commercial use only. The Journal of Rheumatology Copyright $\odot$ (2016. All rights reserved 
12. Berezne A, Ranque B, Valeyre D, Brauner M, Allanore Y, Launay $\mathrm{D}$, et al. Therapeutic strategy combining intravenous cyclophosphamide followed by oral azathioprine to treat worsening interstitial lung disease associated with systemic sclerosis: a retrospective multicenter open-label study. J Rheumatol 2008; 35:1064-72.

13. Launay D, Buchdahl AL, Berezne A, Hatron PY, Hachulla E, Mouthon L. Mycophenolate mofetil following cyclophosphamide in worsening systemic sclerosis-associated lung disease. J Scleroderma Relat Disord 2016 (in press).

14. Khanna D, Brown KK, Clements PJ, Elashoff R, Furst DE, Goldin $\mathrm{J}$, et al. Systemic sclerosis-associated interstitial lung disease - proposed recommendations for future randomized clinical trials. Clin Exp Rheumatol 2010;28 Suppl 58:S55-62.

15. Antoniou KM, Wells AU. Scleroderma lung disease: evolving understanding in light of newer studies. Curr Opin Rheumatol 2008;20:686-91.

16. van Laar JM, Farge D, Sont JK, Naraghi K, Marjanovic Z, Larghero $\mathrm{J}$, et al. Autologous hematopoietic stem cell transplantation vs intravenous pulse cyclophosphamide in diffuse cutaneous systemic sclerosis: a randomized clinical trial. JAMA 2014;311:2490-8.

17. Launay D, Marjanovic Z, de Bazelaire C, Florea L, Zohar S, Keshtmand H, et al. Autologous hematopoietic stem cell transplant in systemic sclerosis: quantitative high resolution computed tomography of the chest scoring. J Rheumatol 2009;36:1460-3.

18. King TE, Jr, Bradford WZ, Castro-Bernardini S, Fagan EA, Glaspole I, Glassberg MK, et al. A phase 3 trial of pirfenidone in patients with idiopathic pulmonary fibrosis. N Engl J Med 2014;370:2083-92.

19. Richeldi L, du Bois RM, Raghu G, Azuma A, Brown KK, Costabel $\mathrm{U}$, et al. Efficacy and safety of nintedanib in idiopathic pulmonary fibrosis. N Engl J Med 2014;370:2071-82.
20. Huang H, Feng RE, Li S, Xu K, Bi YL, Xu ZJ. A case report: the efficacy of pirfenidone in a Chinese patient with progressive systemic sclerosis-associated interstitial lung disease: a CARE-compliant article. Medicine 2016;95:e4113.

21. Udwadia ZF, Mullerpattan JB, Balakrishnan C, Richeldi L. Improved pulmonary function following pirfenidone treatment in a patient with progressive interstitial lung disease associated with systemic sclerosis. Lung India 2015;32:50-2.

22. Gordon J, Udeh U, Doobay K, Magro C, Wildman H, Davids M, et al. Imatinib mesylate (Gleevec) in the treatment of diffuse cutaneous systemic sclerosis: results of a 24-month open label, extension phase, single-centre trial. Clin Exp Rheumatol 2014;32 Suppl 86:S189-93.

23. Pope J, McBain D, Petrlich L, Watson S, Vanderhoek L, de Leon F, et al. Imatinib in active diffuse cutaneous systemic sclerosis: results of a six-month, randomized, double-blind, placebo-controlled, proof-of-concept pilot study at a single center. Arthritis Rheum 2011;63:3547-51.

24. Prey S, Ezzedine K, Doussau A, Grandoulier AS, Barcat D, Chatelus E, et al. Imatinib mesylate in scleroderma-associated diffuse skin fibrosis: a phase II multicentre randomized double-blinded controlled trial. Br J Dermatol 2012;167:1138-44.

25. Khanna D, Albera C, Fischer A, Khalidi N, Raghu G, Chung L, et al. An open-label, Phase II study of the safety and tolerability of pirfenidone in patients with scleroderma-associated interstitial lung disease: the LOTUSS Trial. J Rheumatol 2016;43:1672-9.

26. Costabel U, Bendstrup E, Cottin V, Dewint P, Egan JJ, Ferguson J, et al. Pirfenidone in idiopathic pulmonary fibrosis: expert panel discussion on the management of drug-related adverse events. Adv Ther 2014;31:375-91.

J Rheumatol 2016;43:1619-21; doi:10.3899/jrheum.160887 